\title{
Management of anastomotic biliary stricture after liver transplantation: metal versus plastic stent
}

\section{Antonio Facciorusso ${ }^{a}$, Elena Cecilia Roscab ${ }^{b}$ Adewale Ashimic, Kenneth C. Ugoeze ${ }^{d}$, Utkarsha Pathake, Vanessa Infantef, Nicola Muscatiello ${ }^{a}$}

University of Foggia, Italy; University of Medicine and Pharmacy "Victor Babes" Timisoara, Romania; Federal Medical Centre Birnin Kudu, Jigawa State, Nigeria; University of Port Harcourt, Nigeria; Guru Gobind Singh Indraprastha University, New Delhi, India; University of Sao Paulo, Brazil

\section{Abstract}

${ }^{\mathrm{a}}$ Gastroenterology Unit, Department of Medical Sciences, University of Foggia, Italy (Antonio Facciorusso; Nicola Muscatiello); ${ }^{b}$ Department of Neurology, University of Medicine and Pharmacy "Victor Babes" Timisoara, Romania (Elena Cecilia Rosca); 'Department of Obstetrics and Gynecology, Federal Medical Centre Birnin Kudu, Jigawa State, Nigeria (Adewale Ashimi); ${ }^{\mathrm{d} D e p a r t m e n t}$ of Pharmaceutics \& Pharmaceutical Technology, University of Port Harcourt, Nigeria

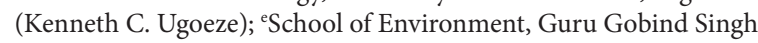
Indraprastha University, New Delhi, India (Utkarsha Pathak); fDepartment of Infectious Diseases, University of Sao Paulo, Brasil (Vanessa Infante)

Conflict of Interest: None

Correspondence to: Antonio Facciorusso, Gastroenterology Unit, Department of Medical Sciences, University of Foggia, Viale L. Pinto 1, 71100 Foggia, Italy, e-mail: antonio.facciorusso@virgilio.it

Received 20 March 2018; accepted 29 June 2018; published online 20 July 2018

DOI: https://doi.org/10.20524/aog.2018.0297

\section{Introduction}

Biliary stricture represents one of the most frequently observed complications after orthotopic liver transplantation (OLT), occurring in $40 \%$ of patients who undergo OLT, particularly those receiving an organ from a living donor [1,2]. After OLT, anastomotic strictures (80\%) are more common than non-anastomotic strictures, which result mainly from hepatic ischemia and are less responsive to endoscopic therapy, requiring a longer duration of endoscopic intervention and sometimes even re-transplantation [3,4].

While recent years have seen significant improvement in the management of anastomotic biliary strictures (ABSs) using balloon dilation and multiple plastic stents, ABSs remain refractory to endoscopic therapy in a non-negligible number of cases, with relatively high rates of recurrence, particularly in the case of late ABSs (presenting later than 
1 month post-OLT) [5-10]. Balloon dilation with stent placement is more effective than balloon dilation alone, and progressively increasing the number of stents placed during subsequent endoscopic retrograde cholangiopancreatography (ERCP) procedures seems to be the most effective treatment approach $[11,12]$. However, although serial balloon dilation and plastic stent exchanges (usually 3 months apart over an extended period) have been used worldwide for several years, the optimal strategy for managing ABSs still needs to be defined $[11,12]$.

Fully-covered self-expandable metal stents (FCSEMS) are already used in clinical practice to treat malignant strictures, and in recent years they have also demonstrated interesting results in the management of benign conditions, including post-OLT ABS [13]. The main potential benefit of FCSEMS is their large caliber and longer duration of patency, allowing them to be left in place longer than plastic stents, thus reducing the need for procedures for serial dilations and stent placement [12].

There is currently limited comparative evidence on the use of FCSEMS with respect to plastic stents in the management of post-OLT ABS. In this systematic review, we performed a pairwise meta-analysis of studies comparing the efficacy of FCSEMS and plastic stents in the resolution of post-transplant ABSs. In addition, we evaluated as secondary outcomes the ABS recurrence rate after stent placement, the treatment time and the safety of the procedure.

\section{Materials and methods}

This meta-analysis was performed in accordance with indications described in the Cochrane Handbook [14] and was conducted according to the Preferred Reporting Items for Systematic reviews and Meta-Analysis (PRISMA) guidelines [15].

\section{Search strategy and selection criteria}

Fig. 1 presents the search strategy followed in the metaanalysis. A computerized bibliographic search was performed on PubMed/Medline, Embase, Google Scholar and Cochrane library databases, independently by two authors (AF, ECR),

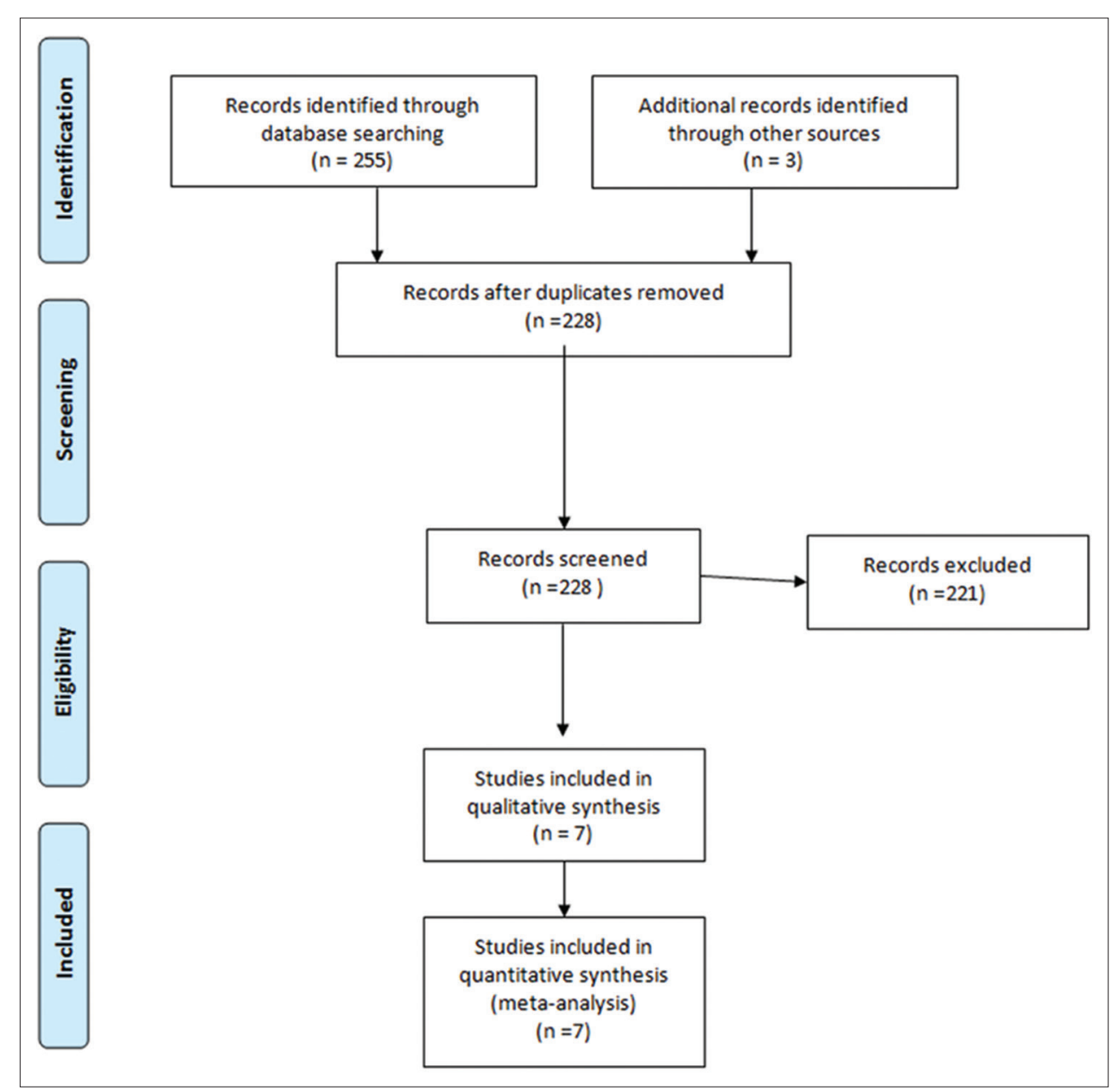

Figure 1 Study selection flow chart 
using the following key words: "anastomotic biliary stricture", "metal stent", "plastic stent" and "ERCP". A complementary manual search was performed by checking the references of all the main review articles on this topic, to identify possible additional studies.

Eligible studies were randomized-controlled trials (RCTs) and retrospective studies published until October 2017 that met the following inclusion criteria: (a) patients: adults undergoing ERCP and with radiologically confirmed diagnosis of post-OLT anastomotic biliary stricture; (b) intervention: ERCP with placement of FCSEMS; (c) comparator: ERCP with placement of multiple plastic stents; and (d) outcomes: stricture resolution as a primary outcome, stricture recurrence, treatment time (defined as time lapse between first and last therapeutic ERCP session), and complication rate as secondary outcomes.

We excluded narrative and systematic reviews [16], studies that did not report any of the main outcomes, and any studies not written in English. When incomplete information was available, attempts were made to contact the corresponding authors for additional data. Disagreements were resolved by discussion and following a third opinion (NM).

The quality of the included studies was assessed by two authors independently (AF, ECR), according to the Cochrane Collaboration's tool for assessing the risk of bias [17] for RCTs and the Newcastle-Ottawa scale [18] for observational studies. Any disagreements were addressed by reevaluation and following a third opinion (NM).

\section{Statistical analysis}

Pairwise meta-analysis was performed using a randomeffects model to estimate the pooled odds ratio (OR) and 95\% confidence interval (CI) [19]. We assessed statistical heterogeneity using the $\mathrm{I}^{2}$ statistic, with values over $50 \%$ indicating substantial heterogeneity, while small study effects were assessed by examining funnel plot asymmetry. Multiple sensitivity analyses were performed to assess the robustness of our findings. These were based on: (a) study design (RCT vs. retrospective), and (b) study quality (moderate vs. low). All calculations were performed using Review Manager 5.3 (the Cochrane Collaboration, Copenhagen, Denmark) and R 3.0.2 (R Foundation for Statistical Computing, Vienna, Austria), "metafor" package.

\section{Results}

\section{Included studies}

From 258 unique studies identified using the search strategy, we included 7,4 RCTs $[20,22,24,25]$ and 3 retrospective studies [21,23,26], whose characteristics are summarized in Table 1. All the retrospective studies were published as congress abstracts $[21,23,26]$, while RCTs were available as full-text papers. Overall, 379 patients were included, of whom 148 underwent ERCP with FCSEMS and 231 were treated with plastic stents. The recruitment period ranged from 2006-2015.

In the FCSEMS studies, the stents were removed at 4-6 months to reassess the stricture and were eventually replaced by new stents, whereas plastic stents were removed and replaced with a new stent at 3 months. The primary outcome, resolution of the stricture, was reported in all of the included studies.

In all the studies the two arms were well-balanced at baseline in terms of main demographic characteristics, as reported in Table 2. The number of procedures per patient and the need for balloon dilation were considerably higher in patients treated with plastic stents, whereas stent migration was usually more frequent in subjects undergoing ERCP with FCSEMS placement (Table 2). Notably, all strictures occurred $>1$ month after OLT and were thus classified as late strictures.

Quality assessment was performed in the context of the primary outcomes, and two retrospective studies $[21,26]$ and 3 RCTs $[22,24,25]$ were considered to be of moderate quality, mainly because of the high risk of performance bias. Overall and study-level quality assessments are summarized in Supplementary Table 1.

\section{Stricture resolution}

Data from six studies with 272 patients were pooled for the analysis of stricture resolution. The study by Morales et al was excluded because it did not report the number of patients, but only the number of procedures [23]. As depicted in Fig. 2, pooled OR was 1.38 (95\%CI $0.60-3.15)$, with no statistical difference between the two procedures $(\mathrm{P}=0.45)$. A low level of heterogeneity was found $\left(\chi^{2}=5.34\right.$, d.f. $\left.=5[\mathrm{P}=0.38], \mathrm{I}^{2}=6 \%\right)$ and no evidence of publication bias was detected by visual examination of a funnel plot (Supplementary Fig. 1A) or with

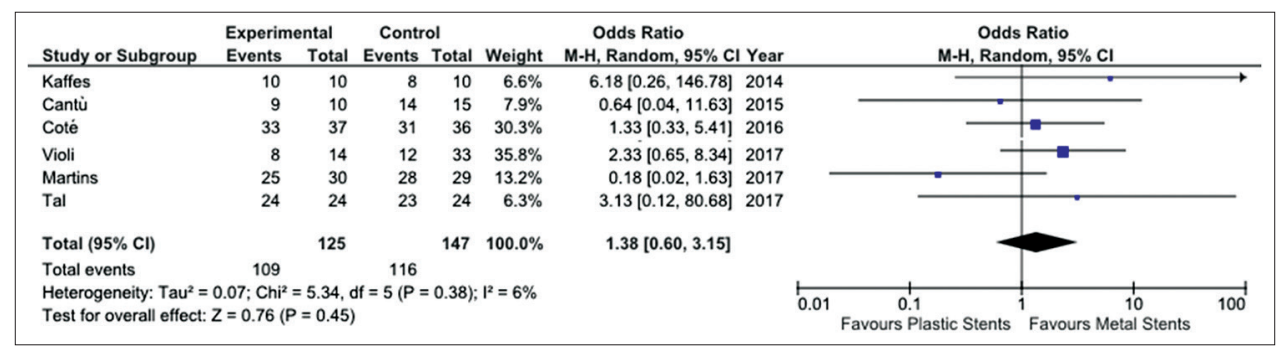

Figure 2 Meta-analysis of stricture resolution between fully-covered self-expandable metal stents and plastic stents 
Table 1 Characteristics of included studies comparing metal and plastic stents

\begin{tabular}{|c|c|c|c|c|c|c|}
\hline Study, year [ref.] & $\begin{array}{l}\text { Study } \\
\text { design }\end{array}$ & Location; Time period & Intervention $(\mathrm{N})$ & $\begin{array}{l}\text { Control } \\
(\mathrm{N})\end{array}$ & Technical aspects & $\begin{array}{l}\text { Relevant } \\
\text { outcomes } \\
\text { reported }\end{array}$ \\
\hline Kaffes, 2014 [20] & RCT & Australia; 2008-2011 & FCSEMS (10) & PS (10) & $\begin{array}{l}\text { FCSEMS } 40 \mathrm{~mm} \\
\text { length and } 10 \mathrm{~mm} \\
\text { width removed at } \\
12 \text { weeks to reassess } \\
\text { the stricture } \\
\text { PS } 10 \mathrm{Fr} \text { reassessed } \\
\text { 3-monthly }\end{array}$ & $\begin{array}{l}\text { Resolution of the } \\
\text { stricture } \\
\text { Recurrence of the } \\
\text { stricture } \\
\text { Treatment time } \\
\text { Complication } \\
\text { rate }\end{array}$ \\
\hline Cantù, 2015 $[21]$ & $\mathrm{R}$ & Italy; NR & FCSEMS (10) & PC (15) & $\begin{array}{l}\text { FCSEMS } 10 \mathrm{~mm} \\
\text { width removed at } \\
4-6 \text { months } \\
\text { PS } 10 \text { Fr reassessed } \\
\text { 3-monthly }\end{array}$ & $\begin{array}{l}\text { Resolution of the } \\
\text { stricture } \\
\text { Treatment time } \\
\text { Complication } \\
\text { rate }\end{array}$ \\
\hline Cotè, 2016 [22] & RCT & USA, UK; 2011-2014 & FCSEMS $(37)^{+}$ & PS $(36)^{+}$ & $\begin{array}{l}\text { FCSEMS } 10 \mathrm{~mm} \\
\text { diameter reassessed } \\
\text { at } 6 \text { months } \\
\text { PS reassessed } \\
\text { 3-monthly }\end{array}$ & $\begin{array}{l}\text { Resolution of the } \\
\text { stricture } \\
\text { Recurrence of the } \\
\text { stricture } \\
\text { Treatment time }\end{array}$ \\
\hline Morales, $2016^{\mathrm{a}}[23]$ & $\mathrm{R}$ & USA; 2006-2014 & FCSEMS $(23)^{*}$ & PS $(84)^{*}$ & $\begin{array}{l}\text { FCSEMS } \\
\text { Straight PS }\end{array}$ & $\begin{array}{l}\text { Resolution of the } \\
\text { stricture } \\
\text { Complication } \\
\text { rate }\end{array}$ \\
\hline Martins, 2017 [24] & RCT & Brazil; 2009-2014 & FCSEMS (30) & PS (29) & $\begin{array}{l}\text { PS reassessed } \\
\text { 3-monthly }\end{array}$ & $\begin{array}{l}\text { Resolution of the } \\
\text { stricture } \\
\text { Recurrence of the } \\
\text { stricture } \\
\text { Treatment time } \\
\text { Complication } \\
\text { rate }\end{array}$ \\
\hline $\mathrm{Tal}, 2017$ [25] & RCT & $\begin{array}{l}\text { Germany, Italy, } \\
\text { Finland; 2012-2015 }\end{array}$ & FCSEMS (24) & PS (24) & $\begin{array}{l}\text { FCSEMS } 10 \mathrm{~mm} \\
\text { diameter reassessed } \\
\text { at } 6 \text { months } \\
\text { PS reassessed } \\
\text { 3-monthly }\end{array}$ & $\begin{array}{l}\text { Resolution of the } \\
\text { stricture } \\
\text { Recurrence of the } \\
\text { stricture } \\
\text { Treatment time } \\
\text { Complication } \\
\text { rate }\end{array}$ \\
\hline Violi, 2017 [26] & $\mathrm{R}$ & Italy; 2004-2014 & FCSEMS (14) & PS (33) & $\begin{array}{l}\text { Single or multiple } \\
\text { PS }\end{array}$ & $\begin{array}{l}\text { Resolution of the } \\
\text { stricture } \\
\text { Treatment time }\end{array}$ \\
\hline
\end{tabular}

${ }^{\mathrm{a}}$ Data reported as congress abstracts; ${ }^{+}$Subgroup of patients with post-transplant anastomotic biliary strictures; ${ }^{*}$ Number of procedures FCSEMS, fully-covered self-expandable metal stent; NR, not reported; $P S$, plastic stent; $R$, retrospective, RCT, randomized controlled trial

Begg and Mazumdar's test $(\mathrm{P}=0.34)$. A sensitivity analysis based on both study design and quality confirmed the main summary estimate (Supplementary Table 2).

\section{Stricture recurrence and treatment time}

Stricture recurrence was reported in 4 studies $[20,22,24,25]$ and showed a non-significant trend in favor of plastic stents (OR 1.82, 95\%CI 0.52-6.31, $\mathrm{P}=0.35)$ with moderate heterogeneity $\left(\chi^{2}=5.17\right.$, d.f. $=3$, $\mathrm{I}^{2}=42 \% ; \mathrm{P}=0.16$ ) (Fig. 3). No evidence of publication bias was found (Supplementary Fig. 1B). Sensitivity analysis confirmed these results across all the subgroups explored (Supplementary Table 2).

Six studies enrolling 272 patients reported data on the comparison of treatment time between FCSEMS and plastic stents (Fig. 4). ERCP with placement of FCSEMS involved a significantly shorter treatment time (mean standardized difference: -3.58 months, $95 \% \mathrm{CI}-6.23$ to $-0.93 ; \mathrm{P}=0.008$ ). It should be noted, though, that the robustness of this finding was impaired by high heterogeneity $\left(\chi^{2}=80.20\right.$, d.f. $=5, I^{2}=94 \% ; P<0.001$; Fig. 4$)$.

A funnel plot did not show any evidence of publication bias (Supplementary Fig. 1C) and sensitivity analysis confirmed the above reported findings, except for the subgroup of retrospective studies (Supplementary Table 2). 


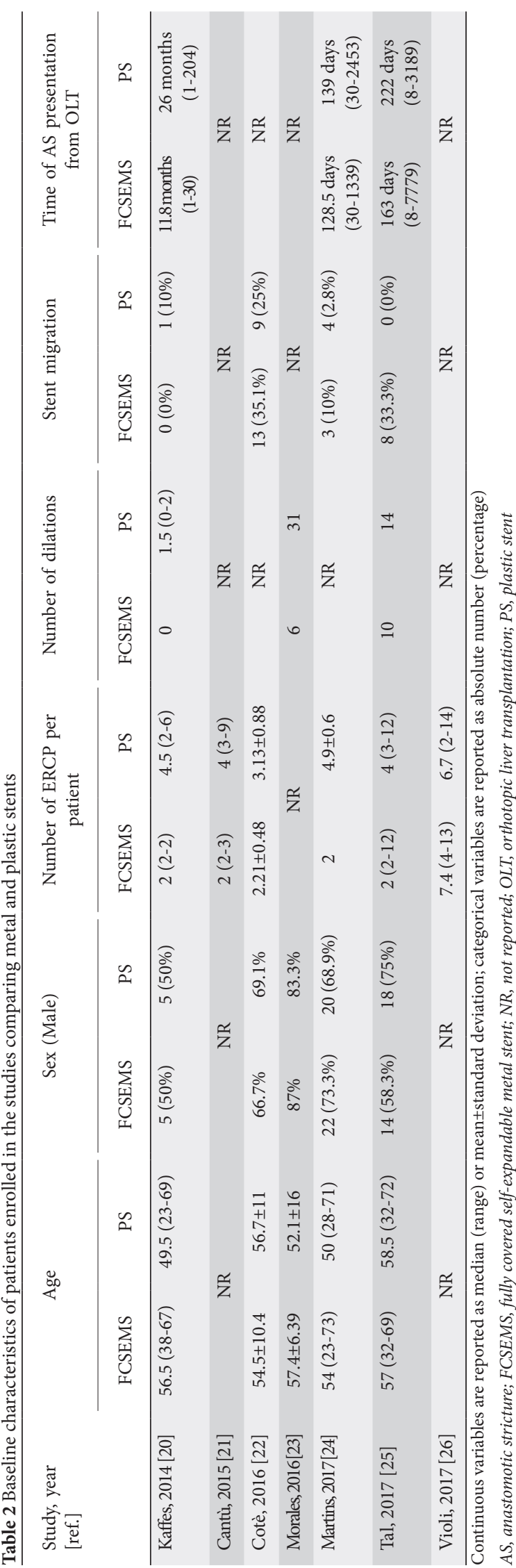

\section{Complication rate}

Five studies reported data on adverse events rate [20,21,23-25]. Complications were more frequent in the FCSEMS group, although not significantly so (OR 2.34, 95\%CI $0.75-7.25 ; \mathrm{P}=0.14)$ and with moderate heterogeneity $\left(\mathrm{I}^{2}=44 \%\right.$, $\mathrm{P}=0.13$; Supplementary Fig. 2). No evidence of publication bias was found (Supplementary Fig. 1D). A detailed list of the complications observed in the two groups is given in Supplementary Table 3. In particular, pancreatitis and postprocedural pain were observed more frequently after FCSEMS. Sensitivity analysis confirmed these results across all the subgroups explored (Supplementary Table 2).

\section{Discussion}

Balloon dilation and plastic stents have significantly improved the endoscopic management of post-OLT ABSs over the past decade, with successful stricture resolution in more than $60 \%$ of cases [16]. However, ABSs after living donor liver transplantation remain refractory to endoscopic therapy in most case series $[5,8]$. Therefore, to overcome the major drawbacks of serial balloon dilations with plastic stent exchanges (need to repeat the procedure over an extended period, considerable rate of recurrence), covered self-expandable metal stents already used for treating malignant strictures have been successfully introduced into clinical practice. In 2013, a systematic review of small case series showed promising results with metal stents [16], but a direct comparison between the two procedures was not feasible because of the lack of head-to-head RCTs.

Through a meta-analysis of 7 studies (including 4 RCTs), to the best of our knowledge the first ever published in this field, we made several key observations. First, the two procedures do not differ in terms of stricture resolution and recurrence, although FCSEMS showed more favorable results concerning ABS resolution and higher recurrence rates; the robustness of these findings is supported by the low level of heterogeneity and their stability in the sensitivity analysis. Second, ERCP with placement of FCSEMS is associated with significantly shorter treatment time, although this result should be interpreted with caution because of the high heterogeneity particularly in terms of pancreatitis and post-procedural pain, not reaching the significance threshold but sounding a note of caution for physicians using this device. Our findings confirm that the main potential benefit of FCSEMS is their large caliber and longer duration of patency, allowing them to be left in place longer than plastic stents and resulting in fewer procedures for serial dilations and placement of multiple plastic stents.

In the past, the use of SEMS (mainly uncovered) in benign biliary strictures was limited by the difficulty of their removal [27]. In recent years, small series have demonstrated the successful use of covered SEMS in the treatment of benign biliary and pancreatic strictures [27-29]. In all these studies, covered SEMS were successfully removed in the majority $(>95 \%)$ of patients. Even in the absence of a clear benefit in 


\begin{tabular}{|c|c|c|c|c|c|c|c|c|c|c|}
\hline \multirow[b]{2}{*}{ Study or Subgroup } & \multicolumn{2}{|c|}{ Metal Stents } & \multicolumn{2}{|c|}{ Plastic Stents } & \multirow[b]{2}{*}{ Weight } & \multirow{3}{*}{$\begin{array}{l}\begin{array}{c}\text { Odds Ratio } \\
\text { M-H, Random, } 95 \% \mathrm{Cl} \text { Year }\end{array} \\
0.86[0.12,5.94] 2014\end{array}$} & \multirow{2}{*}{\multicolumn{4}{|c|}{$\begin{array}{c}\text { Odds Ratio } \\
\text { M-H, Random, } 95 \% \mathrm{Cl}\end{array}$}} \\
\hline & Events & Total & Events & Total & & & & & & \\
\hline Kaffes & 3 & 10 & 3 & 9 & $24.5 \%$ & & & & & \\
\hline Coté & 4 & 33 & 2 & 31 & $27.1 \%$ & $2.00[0.34,11.79] 2016$ & & & & \\
\hline Tal & 5 & 24 & 5 & 23 & $34.3 \%$ & $0.95[0.23,3.83] 2017$ & & & & \\
\hline Martins & 8 & 25 & 0 & 28 & $14.0 \%$ & $27.69[1.50,510.06] 2017$ & & & & \\
\hline Total $(95 \% \mathrm{Cl})$ & & 92 & & 91 & $100.0 \%$ & $1.82[0.52,6.31]$ & & & & \\
\hline Total events & 20 & & 10 & & & & & & & \\
\hline $\begin{array}{l}\text { Heterogeneity: } \mathrm{Tau}^{2}= \\
\text { Test for overall effect: }\end{array}$ & $\begin{array}{l}0.67 ; \mathrm{Chi}^{2} \\
\mathrm{Z}=0.94(\end{array}$ & $\begin{array}{l}=5.17, \\
=0.35\end{array}$ & $\begin{array}{l}d f=3(P= \\
)\end{array}$ & $0.16) ; 1$ & $2=42 \%$ & & 0.01 & $\begin{array}{cc}0.1 & 1 \\
\text { Favours Metal Stents }\end{array}$ & $\begin{array}{c}10 \\
\text { Favours Plastic Stents }\end{array}$ & 100 \\
\hline
\end{tabular}

Figure 3 Meta-analysis of stricture recurrence between fully-covered self-expandable metal stents and plastic stents

\begin{tabular}{|c|c|c|c|c|c|c|c|c|c|c|c|c|c|}
\hline \multirow[b]{2}{*}{ Study or Subgroup } & \multicolumn{3}{|c|}{ Metal Stents } & \multicolumn{3}{|c|}{ Plastic Stents } & \multirow{3}{*}{$\frac{\text { Weight }}{20.3 \%}$} & \multirow{2}{*}{\multicolumn{2}{|c|}{$\begin{array}{l}\text { Mean Difference } \\
\text { IV, Random, } 95 \% \mathrm{Cl} \text { Year }\end{array}$}} & \multirow{2}{*}{\multicolumn{4}{|c|}{$\begin{array}{l}\text { Mean Difference } \\
\text { IV, Random, } 95 \% \mathrm{Cl}\end{array}$}} \\
\hline & Mean & SD & Total & Mean & SD & Total & & & & & & & \\
\hline Kaffes & 3.8 & 1 & 10 & 10.1 & 1 & 10 & & & & & $=$ & & \\
\hline Cantü & 4 & 3.5 & 10 & 8 & 12 & 15 & $9.3 \%$ & $-4.00[-10.45,2.45]$ & 2015 & & $\rightarrow$ & & \\
\hline Coté & 5.2 & 2.9 & 37 & 6.3 & 2.8 & 36 & $19.8 \%$ & $-1.10[-2.41,0.21]$ & 2016 & & d & & \\
\hline Tal & 5.9 & 3.3 & 24 & 7.5 & 3.5 & 24 & $18.7 \%$ & $-1.60[-3.52,0.32]$ & 2017 & & & & \\
\hline Violi & 16.1 & 6.3 & 14 & 15.4 & 11.5 & 33 & $11.7 \%$ & $0.70[-4.43,5.83]$ & 2017 & & & & \\
\hline Martins & 4.4 & 2.2 & 30 & 11.8 & 1.8 & 29 & $20.2 \%$ & $-7.40[-8.42,-6.38]$ & 2017 & & - & & \\
\hline Total $(95 \%$ Cl) & & & 125 & & & 147 & $100.0 \%$ & $-3.58[-6.23,-0.93]$ & & & $\downarrow$ & & \\
\hline $\begin{array}{l}\text { Heterogeneity: } \mathrm{Tau}^{2}= \\
\text { Test for overall effect: }\end{array}$ & $\begin{array}{l}8.82 ; C h \\
z=2.64\end{array}$ & $\begin{array}{l}P=80 . \\
P=0 .\end{array}$ & & & & D1); $1^{2}=$ & & & & -100 & $\begin{array}{c}1 \\
-50 \\
\text { Favours Metal Stents }\end{array}$ & $\begin{array}{c}50 \\
\text { Favours Plastic Stents }\end{array}$ & $\overrightarrow{100}$ \\
\hline
\end{tabular}

Figure 4 Meta-analysis of treatment time between fully-covered self-expandable metal stents and plastic stents

terms of higher efficacy with FCSEMS, the lower need for repeated procedures and reduced treatment time constitute important points of strength to be considered when defining the therapeutic strategy in these patients. In this aspect, our results are in keeping with the current literature in the field of either benign or malignant strictures [30].

Some concerns were raised in the past about the increased migration rate of FCSEMS compared with uncovered SEMS [27]. Unfortunately, since this adverse event was inconsistently reported across the included studies, a reliable comparative assessment of the migration rate between the two procedures was not feasible. Nevertheless, as reported in Table 2, the occurrence of this adverse event was rather similar in the two treatment groups. Other adverse events were mostly mild and easily manageable, with pancreatitis and mild bleeding being the most frequently observed complications.

Our study had certain limitations. First, the relatively low number of studies, in particular RCTs, and the inclusion of both RCTs and retrospective studies necessitate particular caution when interpreting our results, especially in the case of sensitivity analyses, in which generally no more than three studies could be included. Second, there were also limitations in the individual studies, in particular regarding the limited sample size in most of the RCTs, the presence of low-quality studies, or publications in abstract form. Third, some of the main outcomes were unevenly reported across the included RCTs, mainly because of the different study design. Furthermore, there was significant heterogeneity among the studies with respect to the secondary outcomes.

On the other hand, our meta-analysis has several strengths. In fact, all the included studies presented a similar treatment strategy in terms of stents used and therapeutic schedule. Moreover, the absence of heterogeneity in the primary outcomes and the confirmation of our findings in the sensitivity analysis represent further strengths of our study. Finally, all the relevant outcomes were explored, including procedural time, which constitutes an important aspect in daily clinical practice.

\section{Summary Box}

\section{What is already known:}

- Biliary stricture represents one of the most frequently observed complications after orthotopic liver transplantation

- While significant improvement in the management of anastomotic biliary strictures (ABSs) has been achieved in the last years by using balloon dilation and multiple plastic stents, ABSs remain refractory to endoscopic therapy in a non-negligible number of cases

\section{What the new findings are:}

- Fully-covered self-expandable metal stents appear to be a promising and reliable tool that can significantly decrease the treatment time, although there is still no clear evidence of their superiority over plastic stents in terms of better stricture resolution

- Further large prospective randomized trials are warranted to confirm the results of our analysis

In conclusion, despite the aforementioned weaknesses, our meta-analysis represents the first systematic review of the literature published in this field and describes an accurate comparison between the two techniques exploring the main clinical endpoints. Based on our results, FCSEMS appear to be a promising and reliable tool that can significantly decrease treatment time, although there is still no clear evidence of their superiority over plastic stents in terms of better stricture 
resolution. Large RCTs are needed in order to further confirm our results.

\section{References}

1. Graziadei IW, Schwaighofer $H$, Koch $R$, et al. Long-term outcome of endoscopic treatment of biliary strictures after liver transplantation. Liver Transpl 2006;12:718-725.

2. Lee YY, Gwak GY, Lee KH, et al. Predictors of the feasibility of primary endoscopic management of biliary strictures after adult living donor liver transplantation. Liver Transpl 2011;17:1467-1473.

3. Koneru B, Sterling MJ, Bahramipour PF. Bile duct strictures after liver transplantation: a changing landscape of the Achilles' heel. Liver Transpl 2006;12:702-704.

4. Guichelaar MM, Benson JT, Malinchoc M, Krom RA, Wiesner RH, Charlton MR. Risk factors for and clinical course of nonanastomotic biliary strictures after liver transplantation. Am J Transplant 2003;3:885-890.

5. Seo JK, Ryu JK, Lee SH, et al. Endoscopic treatment for biliary stricture after adult living donor liver transplantation. Liver Transpl 2009;15:369-380.

6. Chang JH, Lee IS, Choi JY, et al. Biliary stricture after adult right-lobe living-donor liver transplantation with duct-to-duct anastomosis: long-term outcome and Its related factors after endoscopic treatment. Gut Liver 2010;4:226-233.

7. Tsujino $T$, Isayama $H$, Kogure $H$, Sato $T$, Nakai $Y$, Koike $K$. Endoscopic management of biliary strictures after living donor liver transplantation. Clin J Gastroenterol 2017;10:297-311.

8. Kato H, Kawamoto H, Tsutsumi K, et al. Long-term outcomes of endoscopic management for biliary strictures after living donor liver transplantation with duct-to-duct reconstruction. Transpl Int 2009;22:914-921.

9. Kim TH, Lee SK, Han JH, et al. The role of endoscopic retrograde cholangiography for biliary stricture after adult living donor liver transplantation: technical aspect and outcome. Scand $J$ Gastroenterol 2011;46:188-196.

10. Costamagna G, Tringali A, Mutignani M, et al. Endotherapy of postoperative biliary strictures with multiple stents: results after more than 10 years of follow-up. Gastrointest Endosc 2010;72:551-557.

11. Dumonceau JM, Tringali A, Blero D, et al; European Society of Gastrointestinal Endoscopy. Biliary stenting: indications, choice of stents and results: European Society of Gastrointestinal Endoscopy (ESGE) clinical guideline. Endoscopy 2012;44:277-298.

12. Chathadi KV, Chandrasekhara V, Acosta RD, et al; ASGE Standards of Practice Committee. The role of ERCP in benign diseases of the biliary tract. Gastrointest Endosc 2015;81:795-803.

13. Cantù P, Parzanese I, Balassone V, et al. Management of biliary anastomotic strictures after liver transplantation (BASALT study): a nationwide Italian survey. Liver Transpl 2017;23:257-261.

14. Higgins JPT, Green S. (editors). Cochrane Handbook for Systematic Reviews of Interventions Version 5.1.0 [updated March 2011]. The Cochrane Collaboration, 2011. Available from http:// handbook-5-1.cochrane.org Accessed on October 30, 2017.
15. Moher D, Liberati A, Tetzlaff J, Altman DG; PRISMA Group. Preferred reporting items for systematic reviews and metaanalyses: the PRISMA statement. Ann Intern Med 2009;151:264269, W64.

16. Kao D, Zepeda-Gomez S, Tandon P, Bain VG. Managing the post-liver transplantation anastomotic biliary stricture: multiple plastic versus metal stents: a systematic review. Gastrointest Endosc 2013;77:679-691.

17. Higgins JP, Altman DG, Gøtzsche PC, et al; Cochrane Statistical Methods Group. The Cochrane Collaboration's tool for assessing risk of bias in randomised trials. BMJ 2011;343:d5928.

18. Lo CK, Mertz D, Loeb M. Newcastle-Ottawa Scale: comparing reviewers' to authors' assessments. BMC Med Res Methodol 2014;14:45.

19. DerSimonian R, Laird N. Meta-analysis in clinical trials. Control Clin Trials 1986;7:177-188.

20. Kaffes A, Griffin S, Vaughan R, et al. A randomized trial of a fully covered self-expandable metallic stent versus plastic stents in anastomotic biliary strictures after liver transplantation. Therap Adv Gastroenterol 2014;7:64-71.

21. Cantù P, Parzanese I, Rosa R, Tenca A, Conte D, Penagini R. Fully covered metal stents vs multiple plastic stenting in the treatment of biliary stricture after liver transplantation: cost-effectiveness analysis. United European Gastroenterol J 2015;3:A387.

22. Coté GA, Slivka A, Tarnasky P, et al. Effect of covered metallic stents compared with plastic stents on benign biliary stricture resolution: a randomized clinical trial. JAMA 2016;315:1250-1257.

23. Morales S, Chalhoub WM, Almario JA, et al. Fully covered self-expandable metal stents outperform straight plastic stents in management of benign anastomotic biliary strictures following orthotopic liver transplantation. Gastrointest Endosc 2016;83:AB611

24. Martins FP, De Paulo GA, Contini MLC, Ferrari AP. Metal versus plastic stents for anastomotic biliary strictures after liver transplantation: a randomized controlled trial. Gastrointest Endosc 2018;87:e1-e131.e13.

25. Tal AO, Finkelmeier F, Filmann N, et al. Multiple plastic stents versus covered metal stent for treatment of anastomotic biliary strictures after liver transplantation: a prospective, randomized, multicenter trial. Gastrointest Endosc 2017;86:1038-1045.

26. Violi P, Bortolasi L, Carraro A, et al. Endoscopic treatment of biliary stricture after orthotopic liver transplantation. Gastroenterology 2017; 152:5:S1276.

27. Pfau PR, Pleskow DK, Banerjee S, et al; ASGE Technology Assessment Committee. Pancreatic and biliary stents. Gastrointest Endosc 2013;77:319-327.

28. Neri V, Ambrosi A, Fersini A, Tartaglia N, Lapolla F, Forlano I. Severe acute pancreatitis: clinical forms of different gravity. Ann Ital Chir 2013;84:47-53.

29. Neri V, Fersini A, Ambrosi A, Tartaglia N, Valentino TP. Mildmoderate acute biliary pancreatitis: role of magnetic resonance cholangiopancreatography in preparation of cholecystectomy. Pancreas 2009;38:717.

30. Moss AC, Morris E, Leyden J, MacMathuna P. Do the benefits of metal stents justify the costs? A systematic review and metaanalysis of trials comparing endoscopic stents for malignant biliary obstruction. Eur J Gastroenterol Hepatol 2007;19:1119-1124. 


\section{Supplementary Figures and Tables}
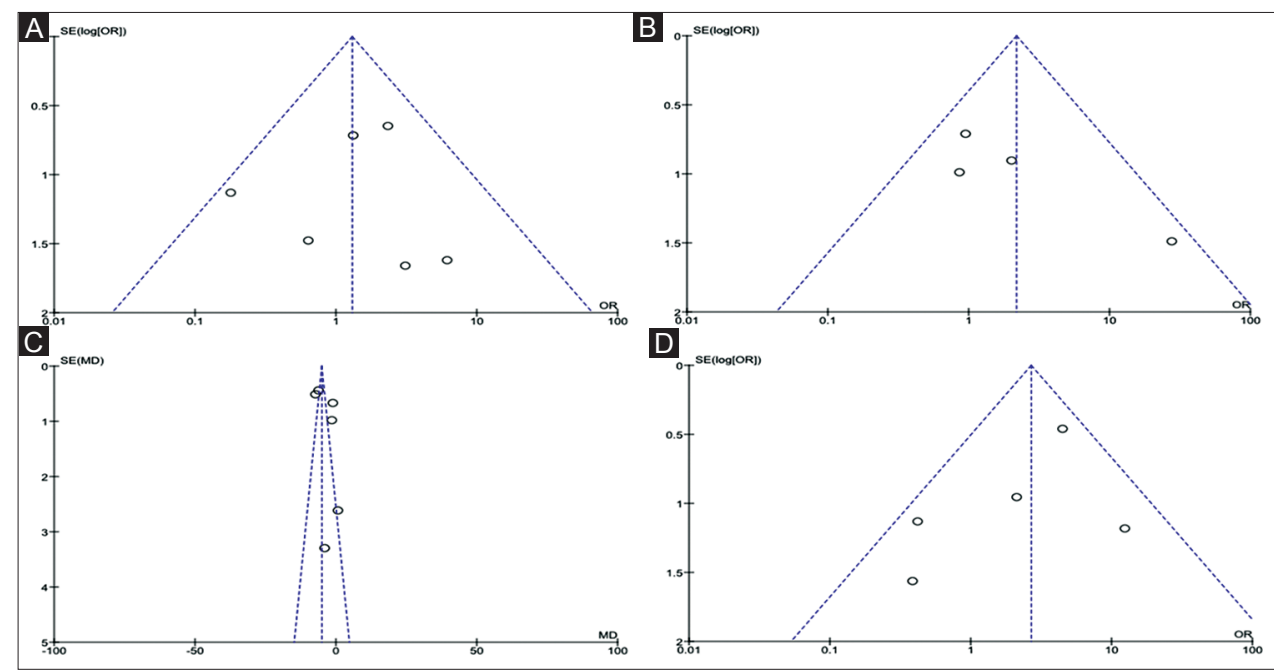

Supplementary Figure 1 Funnel plots for detection of publication bias. (A) Stricture resolution; (B) Stricture recurrence; (C) Treatment time; (D) Complication rate

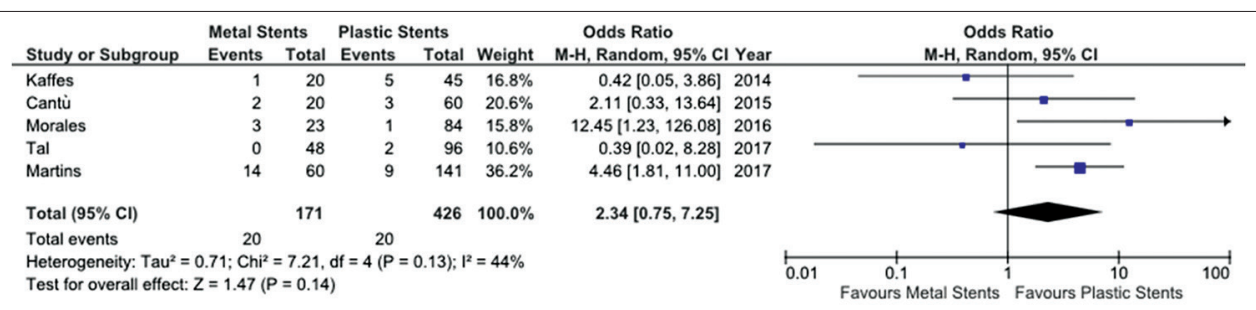

Supplementary Figure 2 Meta-analysis of complication rate comparing fully-covered self-expandable metal stent and plastic stent

Supplementary Table 1 Risk of bias assessment and quality of included studies

\begin{tabular}{lcccc} 
Study, year [ref.] & Selection & Comparability & & Observational studies $^{\mathrm{a}}$ \\
\cline { 3 - 5 } & & & Outcome & Overall quality \\
\hline Cantù $2015[21]$ & $* *$ & $* *$ & $*$ & 4 \\
Morales 2016 [23] & $* *$ & $* *$ & $* *$ & 6 \\
\hline Violi 2017 [26] & $* *$ & & $*$ \\
\hline & Randomized controlled trials & & $*$
\end{tabular}

\begin{tabular}{lcccccccc}
\hline Study, year [ref.] & 1 & 2 & 3 & 4 & 5 & 6 & 7 & L \\
\hline Kaffes, 2014 [20] & H & L & H & H & L & L & L \\
Cotè, 2016 [22] & L & L & H & L & L & L & L & M \\
$\begin{array}{l}\text { Martins, 2017 } \\
{[24]}\end{array}$ & L & L & H & L & L & L & L & M \\
Tal, 2017 [25] & L & L & H & L & L & L & L & M \\
\hline
\end{tabular}

${ }^{a}$ Study quality assessment performed by means of Newcastle/Ottawa scale (each asterisk indicates whether the respective criterion within the subsection was satisfied)

${ }^{\mathrm{b}}$ Cochrane Collaboration's tool for assessing the risk of bias across 7 domains: 1 (Random sequence generation), 2 (Allocation concealment), 3 (Blinding of participants and personnel), 4 (Blinding of outcome assessment), 5 (Incomplete outcome data), 6 (Selective reporting) and 7 (Other bias)

$L$, low; $H$, high; $U$, unclear; $M$, moderate 
Supplementary Table 2 Sensitivity analysis based on (a) study design (RCT vs. retrospective), and (b) quality of studies (moderate vs. low quality)

Device

(a1) RCTs

(a2) Retrospective

(b1) Moderate quality

(b2) Low quality

\begin{tabular}{|c|c|c|c|c|}
\hline \multicolumn{5}{|c|}{ Stricture resolution } \\
\hline \multirow{2}{*}{ FCSEMS vs. PS } & $1.02(0.41-2.57)$ & $1.88(0.59-5.98)$ & $1.15(0.54-2.43)$ & $6.18(0.26-146.78)$ \\
\hline & $\begin{array}{c}\mathrm{P}=0.96 \mathrm{I}^{2}=29 \% \\
4 \text { studies }\end{array}$ & $\begin{array}{c}\mathrm{P}=0.28 \mathrm{I}^{2}=0 \% \\
2 \text { studies }\end{array}$ & $\begin{array}{c}\mathrm{P}=0.72 \mathrm{I}^{2}=10 \% \\
5 \text { studies }\end{array}$ & $\begin{array}{c}\mathrm{P}=0.26 \mathrm{I}^{2}=\mathrm{NA} \\
1 \text { study }\end{array}$ \\
\hline \multicolumn{5}{|c|}{ Stricture recurrence } \\
\hline \multirow{2}{*}{ FCSEMS vs. PS } & $1.82(0.52-6.31)$ & NA & $2.57(0.47-14)$ & $0.86(0.12-5.94)$ \\
\hline & $\begin{array}{c}\mathrm{P}=0.35 \mathrm{I}^{2}=42 \% \\
4 \text { studies }\end{array}$ & NA & $\begin{array}{c}\mathrm{P}=0.28 \mathrm{I}^{2}=57 \% \\
3 \text { studies }\end{array}$ & $\begin{array}{c}\mathrm{P}=0.88 \mathrm{I}^{2}=\mathrm{NA} \\
1 \text { study }\end{array}$ \\
\hline \multicolumn{5}{|l|}{ Treatment time } \\
\hline \multirow[t]{2}{*}{ FCSEMS vs. PS } & $-4.16(-7.14$ to -1.19$)$ & $-1.23(-5.76$ to 3.30$)$ & $-2.81(-6.49$ to 0.87$)$ & $-6.30(-7.18$ to -5.42$)$ \\
\hline & $\begin{array}{c}\mathbf{P}=\mathbf{0 . 0 0 6} \mathrm{I}^{2}=96 \% \\
5 \text { studies }\end{array}$ & $\begin{array}{c}\mathrm{P}=0.60 \mathrm{I}^{2}=20 \% \\
2 \text { studies }\end{array}$ & $\begin{array}{c}\mathbf{P}=\mathbf{0 . 0 5} \mathrm{I}^{2}=94 \% \\
5 \text { studies }\end{array}$ & $\begin{array}{c}\mathbf{P}<0.001 \mathrm{I}^{2}=\mathrm{NA} \\
1 \text { study }\end{array}$ \\
\hline \multicolumn{5}{|c|}{ Complication rate } \\
\hline \multirow[t]{2}{*}{ FCSEMS vs. PS } & $1.26(0.19-8.41)$ & $4.47(0.80-24.91)$ & $2.81(0.98-8.12)$ & $2.25(0.08-63.27)$ \\
\hline & $\begin{array}{c}\mathrm{P}=0.81 \mathrm{I} 2=64 \% \\
3 \text { studies }\end{array}$ & $\begin{array}{c}\mathrm{P}=0.09 \mathrm{I}^{2}=27 \% \\
2 \text { studies }\end{array}$ & $\begin{array}{c}\mathrm{P}=0.06 \mathrm{I}^{2}=22 \% \\
3 \text { studies }\end{array}$ & $\begin{array}{c}\mathrm{P}=0.63 \mathrm{I}^{2}=77 \% \\
2 \text { studies }\end{array}$ \\
\hline
\end{tabular}

Significant values are highlighted in bold

RCT, randomized controlled trial; FCSEMS, fully-covered self-expandable metal stents; PS, plastic stents; NA, not applicable

Supplementary Table 3 Detailed list of complications observed in the two groups

\begin{tabular}{|c|c|c|}
\hline Study, year [ref.] & FCSEMS & PS \\
\hline Cantù, 2015 [21] & NR & NR \\
\hline Morales, 2016 [23] & Pancreatitis: $13 \%$ & Pancreatitis: $1.1 \%$ \\
\hline Violi, 2017 [26] & NR & NR \\
\hline Kaffes, 2014 [20] & Cholangitis : $10 \%$ & $\begin{array}{l}\text { Cholangitis: } 40 \% \\
\text { Pain: } 10 \%\end{array}$ \\
\hline Cotè, 2016 [22] & $\begin{array}{l}\text { Pain: } 3.5 \% \\
\text { Cholangitis: } 3.5 \% \\
\text { Jaundice: } 1.7 \% \\
\text { Anorexia: } 1.7 \% \\
\text { Liver disease: } 1.7 \% \\
\text { Portal vein thrombosis: } 1.7 \% \\
\text { Pseudoaneurysm: } 1.7 \%\end{array}$ & $\begin{array}{l}\text { Pain: } 1.8 \% \\
\text { Cholangitis: } 1.8 \%\end{array}$ \\
\hline Martins, 2017 [24] & $\begin{array}{l}\text { Pain: } 6.7 \% \\
\text { Pancreatitis: } 13.3 \% \\
\text { Bacteremia: } 1.7 \%\end{array}$ & $\begin{array}{l}\text { Pain: } 0.7 \% \\
\text { Pancreatitis: } 2.1 \% \\
\text { Bleeding: } 2.1 \% \\
\text { Bacteremia: } 1.4 \%\end{array}$ \\
\hline Tal, 2017 [25] & None & $\begin{array}{l}\text { Hemobilia: } 4.1 \% \\
\text { Bilio-duodenal fistula: } 4.1 \%\end{array}$ \\
\hline
\end{tabular}

